\title{
Evaluation of a functional hand orthosis combined with electrical stimulation adjunct to arm-hand rehabilitation in subacute stroke patients with a severely to moderately affected hand function
}

Citation for published version (APA):

Franck, J. A., Smeets, R. J. E. M. C., \& Seelen, H. A. M. (2019). Evaluation of a functional hand orthosis combined with electrical stimulation adjunct to arm-hand rehabilitation in subacute stroke patients with a severely to moderately affected hand function. Disability and Rehabilitation, 41(10), 1160-1168. https://doi.org/10.1080/09638288.2017.1423400

Document status and date:

Published: 08/05/2019

DOI:

10.1080/09638288.2017.1423400

Document Version:

Publisher's PDF, also known as Version of record

\section{Document license:}

Taverne

\section{Please check the document version of this publication:}

- A submitted manuscript is the version of the article upon submission and before peer-review. There can be important differences between the submitted version and the official published version of record. People interested in the research are advised to contact the author for the final version of the publication, or visit the $\mathrm{DOI}$ to the publisher's website.

- The final author version and the galley proof are versions of the publication after peer review.

- The final published version features the final layout of the paper including the volume, issue and page numbers.

Link to publication

\footnotetext{
General rights rights.

- You may freely distribute the URL identifying the publication in the public portal. please follow below link for the End User Agreement:

www.umlib.nl/taverne-license

Take down policy

If you believe that this document breaches copyright please contact us at:

repository@maastrichtuniversity.nl

providing details and we will investigate your claim.
}

Copyright and moral rights for the publications made accessible in the public portal are retained by the authors and/or other copyright owners and it is a condition of accessing publications that users recognise and abide by the legal requirements associated with these

- Users may download and print one copy of any publication from the public portal for the purpose of private study or research.

- You may not further distribute the material or use it for any profit-making activity or commercial gain

If the publication is distributed under the terms of Article 25fa of the Dutch Copyright Act, indicated by the "Taverne" license above,

Download date: 26 Apr. 2023 


\title{
Evaluation of a functional hand orthosis combined with electrical stimulation adjunct to arm-hand rehabilitation in subacute stroke patients with a severely to moderately affected hand function
}

\author{
Johan Anton Franck ${ }^{a, b}$, Rob Johannes Elise Marie Smeets ${ }^{c}$ and Henk Alexander Maria Seelen ${ }^{b, c}$ \\ ${ }^{a}$ Department of Brain Injury Rehabilitation, Adelante Rehabilitation Centre, Hoensbroek, the Netherlands; ${ }^{\mathrm{b}}$ Adelante Centre of Expertise in \\ Rehabilitation and Audiology, Hoensbroek, the Netherlands; 'Department of Rehabilitation Medicine, Maastricht University, Research School \\ CAPHRI, Maastricht, the Netherlands
}

\begin{abstract}
Purpose: To investigate the usability and effectiveness of a functional hand orthosis, combined with electrical stimulation adjunct to therapy-as-usual, on functional use of the moderately/severely impaired hand in sub-acute stroke patients.

Materials and Methods: Single case experiment (A-B-A'-design) involving eight sub-acute stroke patients. The functional hand orthosis and electrical stimulation were used for six weeks, four days/week, $45^{\prime} /$ day. Outcome measures: Action_Research_Arm_Test, Intrinsic_Motivation_Inventory.

Results: At group level, patients improved 19.2 points (median value) (interquartile range: $[8.8,29.5]$ points) on the Action_Research_Arm_Test $(p=0.001)$. After correcting for spontaneous recovery and/or therapy-as-usual effects Action_Research_Arm_Test scores still improved significantly (median: 17.2 points; interquartile range: $[5.1,29.2]$ points) $(\bar{p}=0.002)$. At individual level, six patients had improved as to arm-hand skill performance at follow-up $(p<=0.010)$. In one patient, arm-hand skill performance improvement did not attain statistical significance. In another patient, no arm-hand skill performance improvement was observed. Average Intrinsic_Motivation_Inventory sub-scores were between 4.6 and 6.3 (maximum: 7), except for 'perceived pressure/tension' (3.3).

Conclusion: Sub-acute stroke patients who display only little/modest improvement on their capacity to perform daily activities, seem to benefit from training with a dynamic arm orthosis in combination with electrical stimulation. Patients' perceived intrinsic motivation and sense of self-regulation was high.
\end{abstract}

> IMPLICATIONS FOR REHABILITATION

- Arm-hand training featuring the dynamic hand orthosis in combination with electrical stimulation shows a shift from no dexterity to dexterity.

- As to the users' experience regarding the dynamic hand orthosis, patients perceive a high-intrinsic motivation and sense of self-regulation.

- Combining the orthosis with electrical stimulation creates opportunities for a nonfunctional hand towards task-oriented training.
ARTICLE HISTORY

Received 18 May 2017

Revised 27 December 2017

Accepted 29 December 2017

\section{KEYWORDS}

Stroke rehabilitation; upper limb; orthotic devices; single case experimental design; motor skills

\section{Introduction}

Stroke leaves approximately $50 \%$ of its survivors disabled with regard to arm-hand performance, often for the rest of their lives $[1,2]$. An important treatment aim in stroke rehabilitation is to achieve and maintain dexterity, i.e. a clinically relevant improvement in both arm-hand function and arm-hand skill performance. The term 'arm-hand function' (AHF) refers to the 'body function and structure level' of the International Classification of Functioning, Disability and Health (ICF) [3]. The term 'arm-hand skilled performance' (AHSP) refers to the ICF activity level, covering both capacity and performance [4]. Selecting the optimal therapy from a wide range of arm-hand interventions is challenging and depends on, among others, the severity of the AHF impairment and the potential (spontaneous) recovery of the affected arm-hand. These aspects may vary considerably among patients $[5,6]$. In order to simplify this heterogeneity problem concerning arm-hand impairment, a stratification may be used in which dexterity can be roughly classified into three levels, i.e. a mildly, moderately, or severely impaired arm-hand, [7,8]. For this classification, the Utrechtse Arm-hand Test (UAT) can be used [9].

The present study is focused on patients who suffer from a moderately to severely affected arm-hand (UAT score 1 or 2). These patients are insufficiently able to generate voluntary movements to participate in regular arm-hand skill training at the start of rehabilitation [10,11], and are often excluded from clinical effectiveness studies. Especially in the early sub-acute phase after stroke, i.e. between $24 \mathrm{~h}$ till 3 months post-stroke [12], this inability to participate in regular arm-hand skill training may hamper improvement in AHF and AHSP. Within this timespan, patients with a severely impaired arm-hand show an uncertain, non-linear trend as to recovery $[13,14]$ and are often labeled beforehand as having 'low potential' regarding recovery of arm-hand function. 
Next to traditional treatment methods for patients with a moderate to severe arm-hand paresis [5,15], training applications also incorporating assistive devices, like robot-assisted therapy with electrical stimulation [16] or dynamic orthoses fitted to the affected arm-hand to facilitate participation in task-oriented training, are emerging $[17,18]$. In contrast to the growing body of evidence regarding the effectiveness of such specific interventions in persons with a moderately to mildly affected arm-hand [5,19,20], studies into the effectiveness of interventions featuring combinations of task-oriented training methods and assistive devices for the most severely affected group of sub-acute stroke patients are still scarce [21], and the effectiveness of many assistive devices in stroke rehabilitation is still equivocal [22,23]. However, modest results as to the use of dynamic hand orthoses combined with task-oriented training in moderately to severely affected stroke patients have been reported [17,24-26]. Stroke patients who are able to regain wrist and finger extension have sufficient residual voluntary movement ability to work independently with these types of orthoses. However, due to absence of voluntary muscle contraction towards extension and flexion of the wrist and fingers, patients will be unable to execute grasp movements independently.

The application of electrical stimulation, adjuvant to a dynamic orthosis, to provoke normal muscle activation of the fingers while the orthosis keeps the paretic wrist and hand in an optimal position, has already been considered by others $[18,20]$. It is assumed that these devices may assist patients with a moderately to severely affected hand in executing a functional grasp independently, even in the presence of minimal voluntary finger flexion. This, in turn, may enable them to participate in task-oriented training interventions [17,21,27-29]. However, evidence on the effectiveness of the aforementioned approaches remains sparse.

As patients' motivation to train/exercise is correlated to therapy outcome [30], next to studying the effectiveness of a dynamic orthosis combined with electrical stimulation, it is important to investigate whether patients are motivated to work with this combination embedded in a task-oriented training program. Applying multiple devices may demand extra efforts as to time to: (1) calibrate the orthosis to fit the anthropometrics of the affected forearm, wrist, and hand, and (2) fine-tune the electrical stimulation prior to the task-oriented intervention. Furthermore, results as to regaining $\mathrm{AHF}$ and $\mathrm{AHSP}$ dexterity may be uncertain for the patient. Therefore, user experience (i.e. usability), perceived competences and motivational aspects from the patient's perspective (like values and beliefs related to task-oriented training combined with the orthosis and electrical stimulation) should be investigated.

The aim of the present study was:

a. to evaluate to what extent arm-hand skill performance may improve in patients with a moderately to severely affected arm-hand (UAT score 1-2) in the sub-acute stage after a stroke who use a dynamic hand orthosis in combination with electrical stimulation, adjunct to therapy-as-usual, and

b. to assess the clinical usability of a dynamic hand orthosis combined with electrical stimulation, adjunct to therapy-asusual, in patients with a moderately to severely affected armhand (UAT score 1-2) in the sub-acute phase after a stroke.

The following research questions were posed:

1. In which order of magnitude does a six-week training with a dynamic hand orthosis combined with electrical stimulation, adjunct to therapy-as-usual, improve arm-hand skill performance in patients with a moderately to severely affected armhand (UAT score 1-2) in the sub-acute stage after a stroke?

2. To what extent is a dynamic hand orthosis combined with electrical stimulation, adjunct to therapy-as-usual, usable in stroke patients with a moderately to severely affected armhand (UAT score 1 or 2 ) in the sub-acute phase after a stroke?

\section{Methods \\ Study design}

This study featured a multiple baseline single case experimental design (A-B-A' design) [31] involving multiple single cases. From each individual subject, many sequential measurements were recorded. After a baseline (A) period, an experimental intervention (B) was applied. In the subsequent time phase $\left(A^{\prime}\right)$, the effect of this experimental stimulus or intervention relative to baseline values was investigated. The number of measurements during baseline was varied between 3 and 6 (range: 12-30 days). Three measurements were performed during the intervention phase (B) and five during the follow-up phase $\left(A^{\prime}\right)$. Measurements performed in the intervention and follow-up phase were interspaced by two weeks, thus generating a time series per measure for each patient separately (see also Figure 1). A meta-analysis on the pooled single case data was also performed.

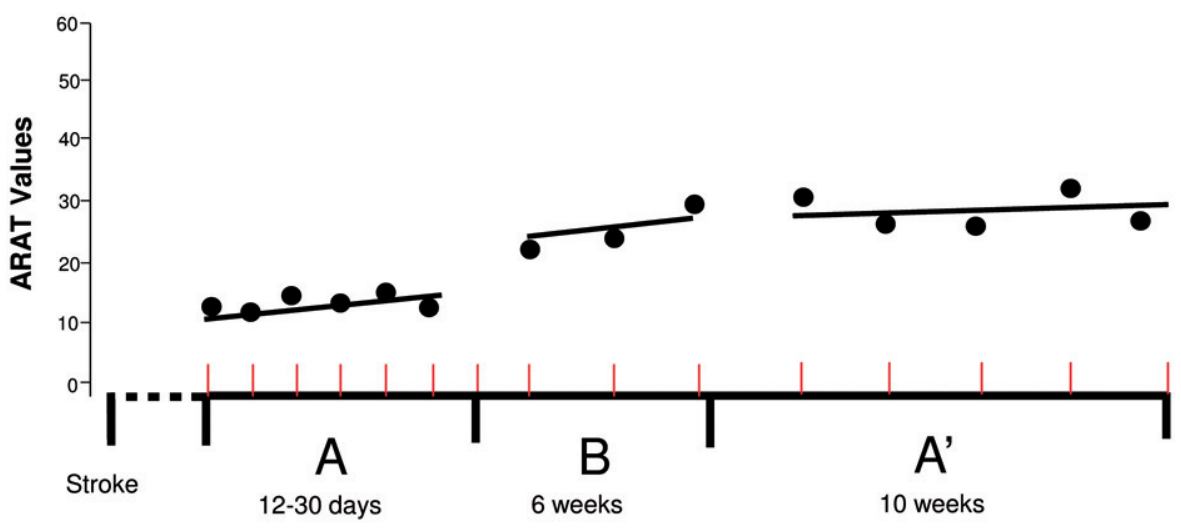

Time $\rightarrow$

Figure 1. Example of linear detrending of the Action Research Arm Test time series of 1 subject. ARAT: Action Research Arm Test; BL: Baseline; TR: Training; FU: Follow-up. 


\section{Subjects}

The study population consisted of eight sub-acute, first-ever stroke patients. All patients were clinically diagnosed with a moderately to severely impaired arm-hand, according to the UAT [9], with an UAT score of 1 or 2 . All patients were admitted to the inpatient stroke ward of Adelante Rehabilitation Centre in Hoensbroek, The Netherlands. Additional inclusion criteria were: age $>=18$ years; patients' post-stroke time less than three months; a fair cognitive level, i.e. being able to understand the questionnaires and measurement instructions; ability to control sitting posture; optimal passive wrist extension of $>5^{\circ}$ (with a minimum of $-5^{\circ}$ ) as measured with the metacarpophalangeal, proximal interphalangeal, and distal interphalangeal joints in extension; the distal part of the affected arm-hand impeded due to hypotonic muscles. Exclusion criteria were: serious problems regarding vision, leading to limited possibilities in object location and object recognition during goal-directed reach and grasp performance; severe problems of the shoulder, arm, or hand on the paretic side, like edema and/or inflammation in the shoulder joint, which hamper the execution of voluntary movements and/or the intensity of training; intolerance regarding the application of electrical stimulation; insufficient understanding of the Dutch language, no informed consent.

Participants were asked for their cooperation, and, after having received adequate information about the study, were enrolled after having given their consent.

\section{Apparatus}

A dynamic hand orthosis (Saeboglove, Saebo Inc, Charlotte, NC) was used. It consists of two parts, (1) a soft Lycra glove and (2) a plastic spiraled forearm shell. The glove assists in finger and thumb extension via tensioners located at all interphalangeal joints of each finger. The plastic forearm shell positions the wrist in a neutral, i.e. functional position. The hand is maintained in an optimal position while grasping. Releasing is facilitated through finger extension just after the grasp movement has ended. The support of hand opening can be adjusted by therapist or the patient, depending on the amount of assistance needed to accomplish tasks. As the patient progresses, the tensioners can be removed individually as needed. When properly fitted, patients should be able to grasp and release different objects sized approximately 2 inches.

An electrical stimulation device, the Microstim 2(v2) (Odstock Medical Limited, Salisbury, Wiltshire) was used additional to the hand orthosis. The electrical stimulation was applied by placing two surface electrodes sized $2 \times 2$ inch. The anode was placed in the forearm midline at approximately one-third of the muscle belly length of the musculus flexor digitorum profundus measured from the belly's proximal end [32].

The cathode was positioned on the muscle belly $5 \mathrm{~cm}$ distally from the anode [33]. The stimulator parameters were adjusted to time phases of $10 \mathrm{~s}$ with $200 \mathrm{usec}$ pulses of $40 \mathrm{~Hz}$, with $10-20 \mathrm{~s}$ silent period between the stimulation epochs. The current intensity was modulated till a tangible contraction of both muscles was present and fingers were flexed in order to produce a grasp movement.

An overview of the training set-up is presented in Figure 2.

\section{Intervention}

During the baseline assessment phase $(A)$, patients received a protocolized arm-hand rehabilitation program (therapy-as-usual), i.e. program 1 of CARAS [34]. This program is designed to teach patients how to cope with a severely impaired, i.e. nonfunctional arm-hand that cannot be used in daily activities. In this program, patients learn strategies to avoid discomfort, to maintain joint mobility and to maintain their muscles/tendons in an optimal condition. Also, they learn strategies as to what to do when discomfort arises, and, during two times $30 \mathrm{~min} /$ week, they learn how to perform basic exercises to elicit voluntary movement where possible. Furthermore, patients learn how to maintain their affected arm-hand in an optimal condition and optimal position during different circumstances. Patients also receive training in the use of supportive tools like static or dynamic splints, braces and/or slings.

Prior to the intervention phase, the orthosis was fitted by a senior occupational therapist or a senior physical therapist. Concomitant with the orthosis, all patients received electrical stimulation. As soon as the patient experienced a comfortable fit of the orthosis, practice conditions were tested in a session, lasting $30 \mathrm{~min}$, to observe if the patient was capable to perform various gross motor grip, grasp, and release exercises independently. Once the patient succeeded, (s)he then entered the intervention phase.

During the intervention phase (B), patients followed a task-oriented training program, i.e. a gross motor grip performance program (program 2 of CARAS) [34] in conjunction with a dynamic hand orthosis (Saeboglove) and electrical stimulation. In this phase, patients learned to integrate their affected arm in daily pursuits. Individual goal-setting and principles of self-efficacy were integrated to enable patients' maximum involvement during training. The duration of the training was $1.5 \mathrm{~h}$ per day, three days per week for six weeks. Training sessions were tailored as follows: Patients started with training on a personal goal for 5-10 min, followed by 45 min of training with the dynamic orthosis, executing various grasp and release exercises. After these 45 min of training, the patient worked 5-10 min towards a personal goal again. Prior to the training sessions, a therapist facilitated the patient with setting-up exercises fitting the patient's goals and current performance level.

During the final $\left(A^{\prime}\right)$ phase, patients continued by following a second and final six-week task-oriented training program, i.e. program 2 of CARAS [25]. In this phase, neither the orthosis nor the electrical stimulation or any other supporting technology was used during arm-hand training.

No other, separate rehabilitation intervention involving the affected arm and hand was applied in the patients during this final phase.

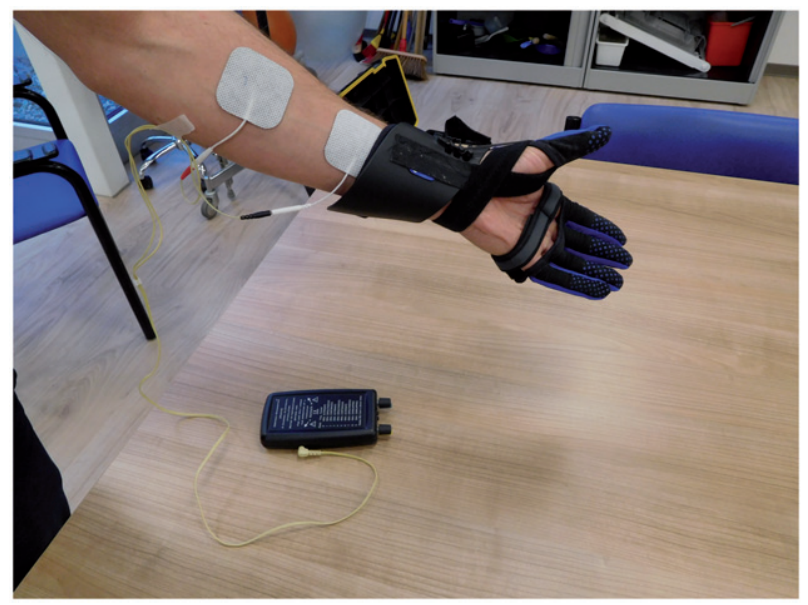

Figure 2. Overview of the treatment set-up. 


\section{Measures}

\section{Utrecht arm/hand test}

The UAT is a simple bedside test measuring arm-hand motor impairment after stroke. Evaluation criteria are comparable to stages of motor recovery after stroke. The ordinal scale represents eight stages, ranging from 0 (nonfunctional arm) to 7 ('clumsy hand') [9]. In the present study, the UAT was used as a classification measure at baseline.

\section{Action research arm test}

The Action Research Arm Test (ARAT) is a capacity test [4] regarding upper extremity activity. It consists of four subtests comprising 16 grasp movements and three reaching movements to be performed by the patient. Items are scored on a four-point scale, its sum score ranging from 0 to 57. The test is valid [35], reliable [36], and sensitive to change [37] in patients with stroke. The ARAT is suitable for the evaluation of changes in arm-hand skills capacity in clinical trials [38]. The minimum clinically important differences (MCID) of the ARAT were 12 points (affected dominant arm-hand) and 17 points (affected non-dominant arm-hand [39].

\section{Intrinsic motivation inventory}

The Intrinsic Motivation Inventory (IMI) assesses participants' subjective experience related to a target activity. It has been used in several experiments related to intrinsic motivation and self-regulation $[40,41]$. In this study, 35 items extracted from the original 45 items of the IMI have been used (see appendix). The subscale 'Perceived choice' and three questions from the last subscale, i.e. 'Relatedness', have been excluded, since no single participant was able to elicit voluntary hand movements at the initial phase of this study and they all chose to participate in the intervention prior to the start of the study. The three questions removed from the last section, Relatedness, were aimed at interactions between persons, and therefore were less relevant to the research question. The seven-point Likert scale instrument was administered at the end of the follow-up phase to assess participants' interest/enjoyment, perceived competence, effort, value/ usefulness, pressure/tension, and relatedness felt while training with the dynamic spring-loaded hand orthosis. Please note that the item "pressure/tension felt" is scored inversely, relative to all other items of the IMI $[40,41]$. The reliability of the IMI was found to be good [42].

\section{Data analysis and statistics}

The intervention (phase B) started at different time periods poststroke due to the baseline lengths (phase A) differing between individual subjects (=multiple baseline design) [31]. This was done to methodologically ensure that the possible temporal causal relationship between the start of the intervention (phase B) and the occurrence of an effect of this intervention may become clear relative to any effects that may be observed during baseline (phase A) caused by e.g. spontaneous recovery and/or conventional therapy received.

In a first data analysis step, baseline data stability and any baseline trends regarding the ARAT, i.e. the average change between consecutive baseline measurement dates, were calculated per subject. Within-group differences between mean baseline data, mean training phase data, and mean follow-up data were analyzed using a Friedman two-way analysis of variance by ranks. Subsequent multiple comparison involved Wilcoxon signed ranks tests in a Bonferroni approach, thus correcting for spurious false positive findings.

Secondly, by using a least squares method, all ARAT data in the time series were linearly adjusted for baseline trends per subject to compensate for improvements caused by e.g. spontaneous recovery and/or conventional therapy received. The residuals, i.e. the detrended (and thereby rendered mutually independent) data, were subsequently analyzed for the whole group using a Kruskal-Wallis one-way analysis of variance test, and, where applicable, followed by multiple comparison involving Mann-Whitney $U$-test.

Thirdly, the linear detrended ARAT time series (i.e. series of residuals) of each individual patient was analyzed separately, i.e. per subject, the residual baseline measurement results were compared to the residual follow-up measurement results using Mann-Whitney U-tests.

Patients' experience and motivation are reported descriptively.

Linear detrending of the ARAT data was performed using MATLAB software (The MathWorks Inc, Natick, MA, USA). All data were statistically analyzed using IBM SPSS software version 23 (IBM Inc, Houston, TX, USA).

\section{Results}

\section{Error analysis}

Eight patients participated in this study. No data were missed during data acquisition. No adverse events were reported during the study.

\section{Participants' characteristics}

All patients were in the early sub-acute phase after stroke, i.e. between $24 \mathrm{~h}$ till three months post-stroke. Patients' characteristics at entry in the study are presented in Table 1.

\section{Baseline data stability}

Three (P3, P7, and P8) of the eight patients showed small improvements (i.e. one point) on the UAT during the baseline phase, whereas only one patient (P5) improved on the ARAT (by 6 points) during the baseline phase. Further improvements at baseline level were not present.

Table 1. Patient characteristics at entry in the study.

\begin{tabular}{|c|c|c|c|c|c|c|c|c|}
\hline Patient & Gender & Age (year) & UAT & ARAT & Post-stroke time (weeks) & Stroke type/lesion side & Dominant side & Impaired side \\
\hline 1 & $M$ & 50 & 1 & 0 & 3 & Ischemic/ACM & $\mathrm{R}$ & $\mathrm{R}$ \\
\hline 2 & M & 59 & 2 & 6 & 5 & Ischemic/ACM & $\mathrm{R}$ & $\mathrm{R}$ \\
\hline 3 & $\mathrm{~F}$ & 48 & 2 & 0 & 4 & Ischemic/lacunar & $\mathrm{R}$ & $\mathrm{R}$ \\
\hline 4 & M & 67 & 2 & 0 & 5 & Ischemic/ACM & $\mathrm{R}$ & $\mathrm{L}$ \\
\hline 5 & M & 66 & 2 & 3 & 8 & Ischemic/ACM & $\mathrm{R}$ & $\mathrm{L}$ \\
\hline 6 & M & 56 & 1 & 0 & 13 & Ischemic/ACM & $\mathrm{R}$ & $\mathrm{L}$ \\
\hline 7 & $\mathrm{~F}$ & 49 & 1 & 0 & 7 & Ischemic/basal ganglia & $\mathrm{R}$ & $\mathrm{L}$ \\
\hline 8 & $\mathrm{M}$ & 72 & 1 & 0 & 4 & Ischemic/corona radiata & $\mathrm{R}$ & $\mathrm{R}$ \\
\hline Mean (sd) & & $58.4(9.2)$ & 1.5 & 1.1 & $6.1(3.2)$ & & & \\
\hline
\end{tabular}




\section{ARAT results}

General improvement over time

Boxplots of ARAT mean results are presented in Figure 3(a). Overall, patients improved over time regarding the ARAT $(p=0.001)$. Furthermore, significant improvements were found between baseline phase (BL) and follow-up phase (FU) $(p=0.012)$, baseline phase and training phase (TR) $(p=0.012)$, and between TR and FU $(p=0.017)$.

\section{Improvement over time, corrected for baseline trends}

Representing data of the whole group $(n=8)$, boxplots of the within-subject averaged ARAT time series data for all three phases, i.e. baseline, training, and follow-up phase, linearly detrended for the baseline trends, are presented in Figure 3(b).

An overall improvement was found for the ARAT results $(p=0.002)$. Multiple comparisons revealed that ARAT residuals were higher in FU relative to those obtained from $\mathrm{BL}(p=0.010)$ and higher in TR relative to those obtained from BL $(p<0.000)$. No statistical differences in ARAT data were found between TR and FU $(p=0.293)$.

\section{Time series for individual participants}

In Figure 4, the baseline trend-corrected time series concerning the ARAT data per patient are depicted.

Furthermore, boxplots of ARAT time series residuals for the baseline (BL), training phase (TR), and follow-up phase (FU) are presented in Figure 5(a,b).

In six of the eight patients (P1-P4, P6-P7) mean (and median) ARAT residuals were higher $(p<=0.010)$ in the FU relative to the $B L$. One patient (P8) also improved in the $F U$ relative to the $B L$, but this improvement did not attain the level of statistical significance $(p=0.020)$. In one patient (P5), a decrease, though not statistically significant, in mean (and median) ARAT residuals was observed between the baseline phase and follow-up phase $(p=0.251)$. Six of the eight patients (P1-P4, P6-P7) also showed a statistically significant improvement between $B L$ and $T R$ $(p<=0.019$ ). One patient (P8) improved over time, although this improvement did not attain significance level $(p=0.034)$. One patient (P5) did not improve between BL and TR $(p=0.101)$. Between the TR and FU phase, no statistically significant improvements in ARAT residuals were observed.

With respect to the non-dominant and dominant hand, minimal clinically important difference (MCID) values differ. Three out

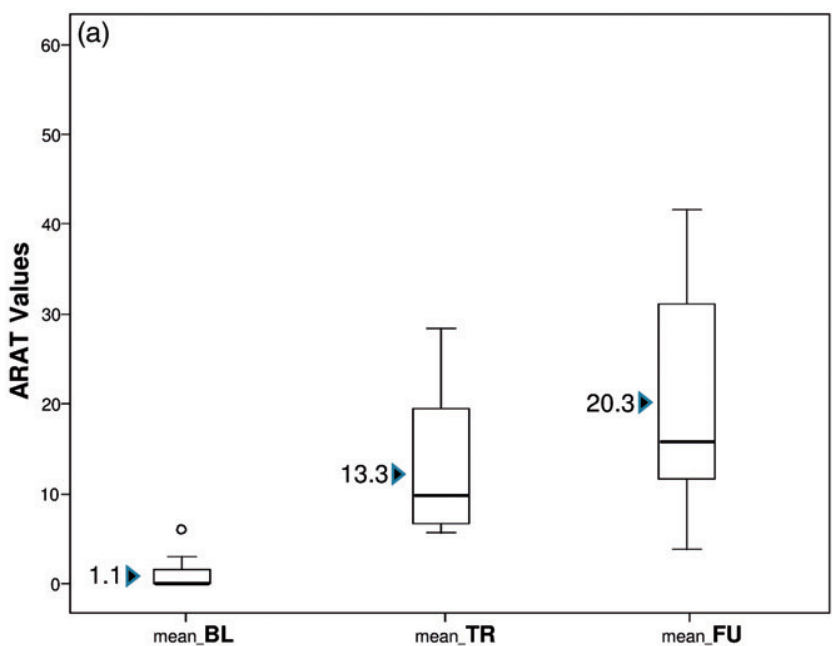

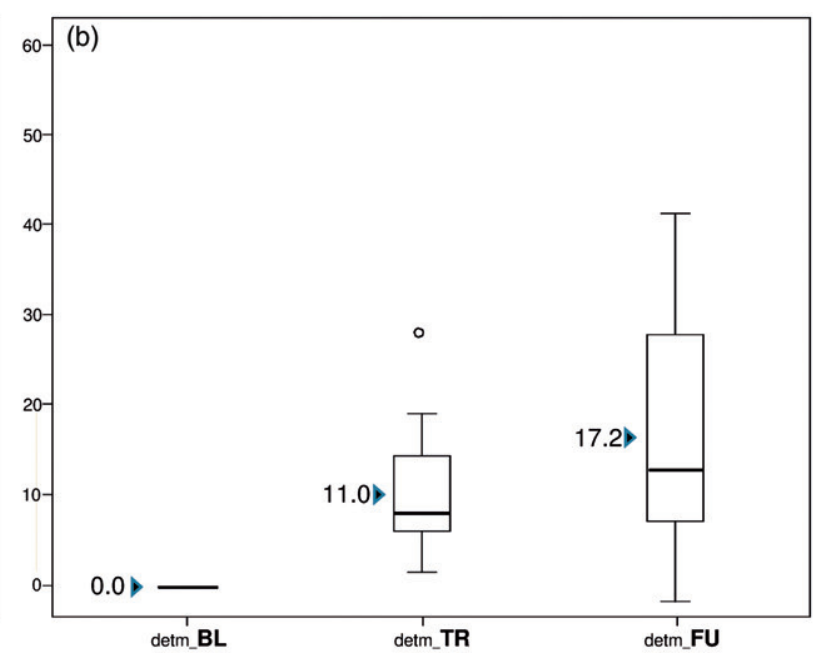

of the eight patients who participated in this study exceeded the MCID threshold regarding the ARAT scores.

In Table 2, mean IMI results are displayed.

Intrinsic motivation and self-regulation values, as measured by the IMI, were relatively high for 3 of the $6 \mathrm{IMI}$ 'sub items, i.e. 'value/usefulness' (6.3/7.0), 'effort/importance' (5.1/7.0), and 'relatedness' (4.9/7.0). The sub-item'Experienced Pressure and Tension' was scored relatively low (3.3/7.0).

\section{Discussion}

The aim of this study was: $(A)$ to evaluate in which order of magnitude AHSP may improve in sub-acute stroke patients with an moderately to severely affected arm-hand (UAT score of 1 or 2), who use a dynamic hand orthosis in combination with electrical stimulation within a six-week task-oriented training program, and (B) to assess the clinical usability of the dynamic hand orthosis combined with electrical stimulation, adjunct to therapy-as-usual, in patients with a moderately to severely affected arm-hand in the sub-acute phase after stroke.

As a result of the arm-hand training featuring the dynamic hand orthosis in combination with electrical stimulation, $75 \%$ of the sub-acute stroke patients improved on their capacity to use their affected arm in daily activities between the start of the training and follow-up. However, as all eight participants were included during the sub-acute phase after stroke, the improvements in arm-hand skill performance may also be attributable to other factors, i.e. (a) spontaneous recovery, (b) received therapyas-usual, (c) the application of the dynamic orthosis in combination with electrical stimulation, or (d) a combination of these factors.

In order to reduce the influence of spontaneous recovery and possible therapy-as-usual effects on the data obtained, two methodological approaches were used. First, a 'multiple baseline across subjects' design was used. Secondly, data series were detrended for any baseline trend for each subject in order to identify the unique contribution of the applied intervention.

As to differences between baseline and follow-up phase, the trend-corrected ARAT data (or 'ARAT residuals') showed that, at group level, significant improvement in arm-hand skills capacity occurred. This suggests that patients with a moderately to severely impaired hand function at the initial start of the intervention can regain a certain level of dexterity at follow-up that may

Figure 3. Boxplots of Action Research Arm Test results. 
be attributed to the use of the dynamic orthosis in combination with electrical stimulation embedded in a task-oriented training program.

As to each individual patient's baseline detrended time series, six out of the eight patients demonstrated significant improvements in arm-hand skills capacity, indicating that they had benefitted from the orthosis in combination with electrical stimulation. In three out of these six patients arm-hand skills capacity improved to such an extent that it enabled them to routinely perform grasp and displace tasks as well as bimanual
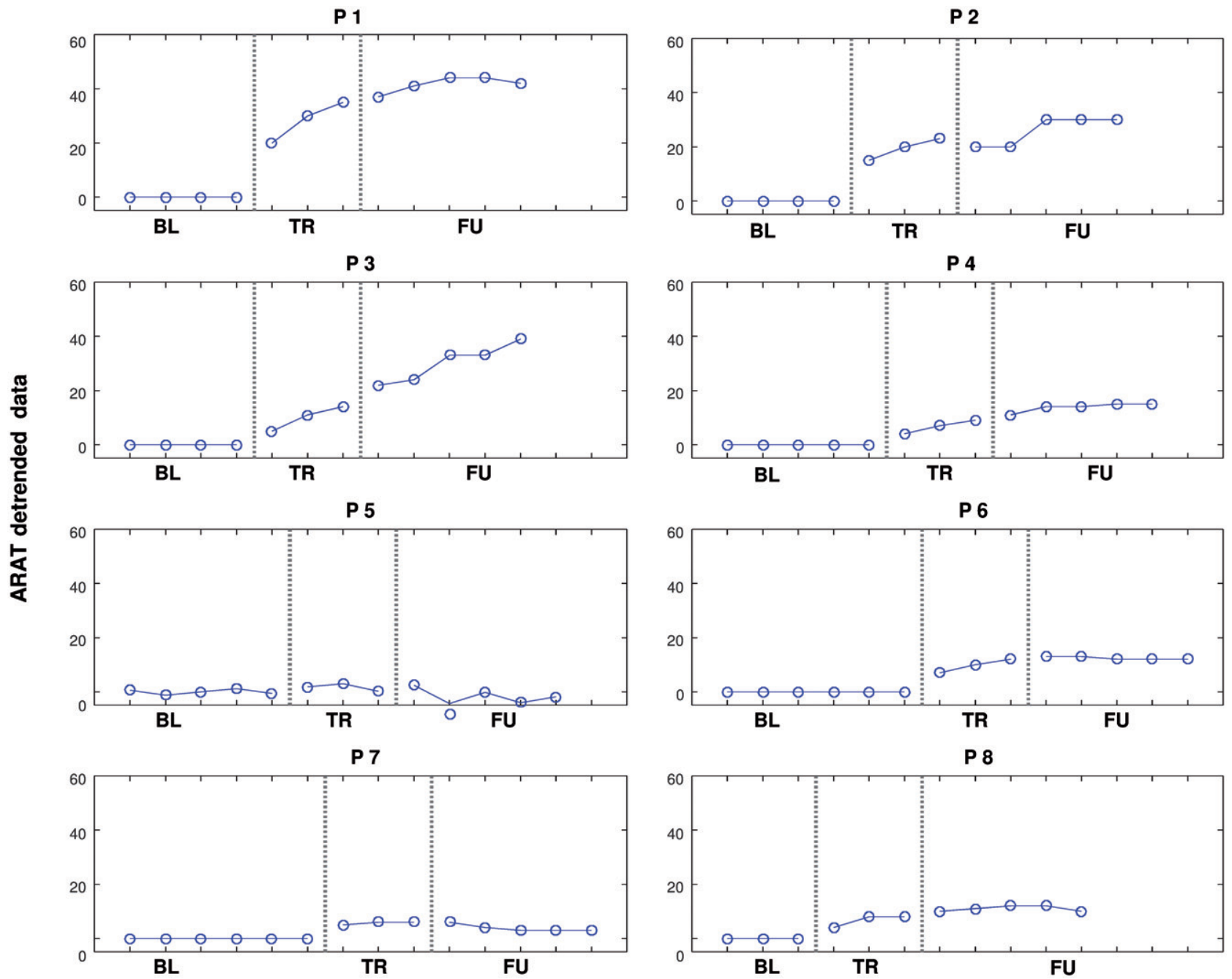

Figure 4. Baseline trend-corrected time series concerning the Action Research Arm Test data

Baseline trend-corrected time series concerning the Action Research Arm Test data of all eight individuals for all three phases. BL: Baseline; TR: Training; FU: Follow-up
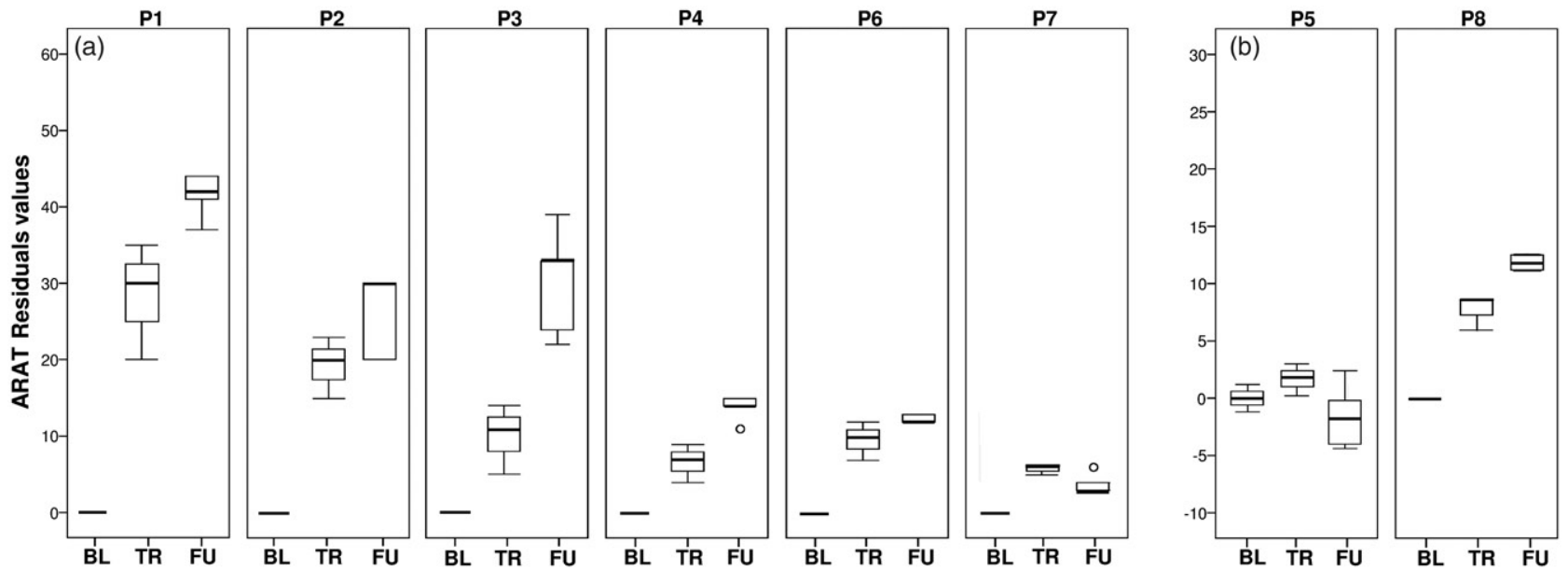

Figure 5. Boxplots of Action Research Arm Test time series residuals.

Action Research Arm Test within-subject residuals for all subjects for the baseline phase and the follow-up phase (5a-b). BL: Baseline; TR: Training; FU: Follow-up 
Table 2. Overview of intrinsic motivation inventory scores.

\begin{tabular}{lr}
\hline Intrinsic motivation inventory item & Mean (sd) \\
\hline Interest/enjoyment & $4.6(0.9)$ \\
Perceived competence & $4.6(1.1)$ \\
Effort/importance & $5.1(0.5)$ \\
Pressure/tension & $3.3(0.5)$ \\
Value/usefulness & $6.3(0.9)$ \\
Relatedness & $4.9(1.4)$ \\
\hline
\end{tabular}

activities. The other three patients improved to a level, which enabled them to perform gross motor grip function, i.e. being able to use their affected arm-hand for passive and active stabilization tasks like fixating bread while making a sandwich. However, one patient did not benefit from the orthosis in combination with the electrical stimulation at all. During the first two weeks of training, this patient experienced an increase in muscle tone and spasticity in the forearm and finger flexors, hampering him in the task-oriented training. Finally, one patient showed clinically relevant, though statistically non-significant improvements in arm-hand skills capacity. The overall results of the present study are in line with Barry et al. [43]; and Franck et al. [24]; who found that stroke survivors with a moderately to severely affected armhand improved significantly on the ARAT after they received armhand training in conjunction with a dynamic orthosis.

The present study showed that, at group level, improvements in arm-hand skills capacity between the training phase and follow-up phase were considerable, though not statistically significant. The latter was mainly due to large inter-individual differences as gauged by the ARAT. From our finding, one might conclude that the majority of patients who improved during the training phase were able to at least maintain their arm-hand skill capacity level during the follow-up phase. Some of these patients even improved further as to arm-hand capacity during the followup phase.

In general, patients were motivated to work with the orthosis and electrical stimulation within the task-oriented training program that lasted 6 weeks. The relative high-score regarding 'value' and 'usefulness' may indicate that patients were capable to work actively and independently with their affected arm and hand during training sessions. Most patients became more competent in the orthosis fitting procedure and (re)adjustments of the orthosis, leading to the device being more useful to them. The patients' growing belief in their own capabilities to become more skilled in the orthosis' fitting procedure and the use of the orthosis within arm-hand therapy may have positively influenced their general sense of self-efficacy [44]. This, in turn, may stimulate each patient to engage even more in his own rehabilitation program and in the use of his affected arm in daily pursuits, thus also preventing 'learned non-use' once he has returned to his home environment.

In this study, the application of the Saeboglove dynamic hand orthosis was combined with electrical stimulation and task-oriented training (CARAS) [34], in which patients were encouraged to work as independently as possible. Studies into the effectiveness of assistive arm-hand devices applied in arm-hand rehabilitation are upcoming $[18,23,45,46]$.

The majority of these orthoses are actuated devices tested in acute, sub-acute, and chronic stroke patients, but mainly in research conditions [18,45]. The randomized controlled trial of Kutner et al. [28] indicated that robot-assisted rehabilitation combined with task-oriented training enhances distal motor function of the wrist and fingers. However, study participants had some voluntary hand movements, i.e. $\geq 10$ degrees of wrist/finger extension. The Rehand [47] is a dynamic hand orthosis, which can be used easily during arm-hand skill performance tasks within rehabilitation practice. Due to its actuated finger-flexion and extension movements, it may assist stroke survivors with no discernible voluntary motion in using their affected hand. However, as a grasp and release motion is generated by forearm and (intrinsic) hand muscle groups [47], some cortical connectivity between these muscles and the affected side of the brain should be present.

In stroke survivors with a severely affected arm-hand, the application of electrical stimulation to improve arm-hand function has been proven to be non-beneficial [48]. In a case-report, MarquezChin et al. [49] combined functional electrical stimulation with a neuro-prosthesis to restore AHF and AHSP in a severely affected stroke patient. Clinical relevant changes were observed at arm function level, but not at the level of dexterity of the severely affected hand [49].

In the present study, the use of a non-actuated orthotic device in combination with electrical stimulation was found to be a valuable addition in arm-hand rehabilitation in 6 out of 8 patients with a severely affected hand in the sub-acute phase post stroke. This is in line with a study by Popovic et al, who combined orthotic systems with electrical stimulation to assist movements coupled to task-oriented training, and with Carpaneto et al. $[20,50]$.

Somatosensory dysfunction, expressed as lack of voluntary finger movements, prevents arm-hand recovery [51]. Despite upcoming clinically useful prediction models $[6,7,14,52]$, it remains difficult to reliably characterize those patients with a severe arm disability who will achieve a clinically important change during arm-hand training and those who will not [53,54]. Systematic monitoring during the first 8 to 12 weeks post-stroke onset has been advocated to identify subgroups of patients who might achieve dexterity in this limited time-window [51,55].

The average time that the eight patients in our study entered the training phase was 7.6 weeks post-stroke onset. Prior to this intervention, all patients coped with a moderately to severely affected arm-hand, i.e. they did not show any arm-hand dexterity. Only voluntary movements in flexion synergy in the proximal and/ or distal part of the arm (UAT 1-2) were observed. Once patients left the training phase, $75 \%$ of these patients had regained and maintained a certain level of arm-hand dexterity.

The present study shows that combining the orthosis with electrical stimulation allows patients to shift from a training condition in which they learn how to cope with a nonfunctional hand, i.e. program 1 of CARAS [34], towards participating within a taskoriented environment, i.e. program 2 of CARAS. This combination of therapy interventions may be a solution for patients with a moderately to severely affected arm-hand who otherwise might not recover functionally, as described in literature [51]. Where normally these patients had to cope with an uncertain prognosis as to attaining a certain level of arm-hand capacity or dexterity, we now should work on the early identification of the subgroup of patients that may have the potential to regain arm-hand dexterity within the sub-acute phase post-stroke, who might benefit from the therapy approach investigated in the present study. This, in turn, may lead to innovative insights to develop novel therapy methods or to adjust and combine existing therapy methods.

\section{Considerations and future research}

Measuring changes in arm-hand skill performance of moderately and severely impaired stroke patients is important. However, it would also have been interesting to investigate how these results 
may be associated with outcome at the 'body and structure level' and the 'participation' level of the International Classification of Functioning (ICF) [56]. Another consideration is that generalizability of the results from a single case experimental design, as used in the present study, towards larger groups of patients, is limited.

The fact that one of the eight patients, i.e. patient P8, showed clinically relevant progressions that did not attain a statistical significance level, may possibly have been due to a lower number of baseline measurements (i.e. $n=3$ ) in this individual. In future research in this domain, it is advocated that baseline length should include at least four measurement points.

Future research should focus on: (1) optimizing arm-hand recovery models in order to assist therapists in identifying, at an early stage post-stroke, which patients might benefit from the application of assistive devices within arm-hand rehabilitation, and (2) larger scale clinical research (e.g. randomized clinical trials) into the effectiveness of assistive devices in stroke survivors in the sub-acute phase with a moderately to severely impaired arm-hand associated with loss of dexterity.

\section{Acknowledgements}

We are grateful to all patients who participated in this study and to all therapists who contributed to this study.

\section{Disclosure statement}

We have the following interests: JAF and HAMS are employed by Adelante. There are no patents, products in development or marketed products to declare.

\section{References}

[1] Broeks JG, Lankhorst GJ, Rumping K, et al. The long-term outcome of arm function after stroke: results of a follow-up study. Disabil Rehabil. 1999;21:357-364.

[2] Shelton FN, Reding MJ. Effect of lesion location on upper limb motor recovery after stroke. Stroke. 2001;32:107-112.

[3] World_Health_Organization. International classification of functioning, disability and health: ICF. Geneva: World Health Organization; 2001.

[4] Lemmens RJ, Timmermans AA, Janssen-Potten $Y J$, et al. Valid and reliable instruments for arm-hand assessment at ICF activity level in persons with hemiplegia: a systematic review. BMC Neurol. 2012;12:21.

[5] Hayward K, Barker R, Brauer S. Interventions to promote upper limb recovery in stroke survivors with severe paresis: a systematic review. Disabil Rehabil. 2010;32:1973-1986.

[6] Nijland $\mathrm{RH}$, van Wegen EE, Harmeling-van der Wel BC, et al. Presence of finger extension and shoulder abduction within 72 hours after stroke predicts functional recovery: early prediction of functional outcome after stroke: the EPOS cohort study. Stroke. 2010;41:745-750.

[7] Duncan PW, Goldstein LB, Horner RD, et al. Similar motor recovery of upper and lower extremities after stroke. Stroke. 1994;25:1181-1188.

[8] Roh J, Rymer WZ, Beer RF. Evidence for altered upper extremity muscle synergies in chronic stroke survivors with mild and moderate impairment. Front Hum Neurosci. 2015;9:6.

[9] Kruitwagen-van Reenen ET, Post MW, Mulder-Bouwens K, et al. A simple bedside test for upper extremity impairment after stroke: validation of the Utrecht arm/hand test. Disabil Rehabil. 2009;31:1338-1343.

[10] Canning CG, Ada L, O'Dwyer NJ. Abnormal muscle activation characteristics associated with loss of dexterity after stroke. J Neurol Sci. 2000;176:45-56.

[11] Taub E, Miller NE, Novack TA, et al. Technique to improve chronic motor deficit after stroke. Arch Phys Med Rehabil. 1993;74:347-354.

[12] Veerbeek JM, van Wegen E, van Peppen R, et al. What is the evidence for physical therapy poststroke? A systematic review and meta-analysis. PloS One. 2014;9:e87987.

[13] Winters C, van Wegen EE, Daffertshofer A, et al. Generalizability of the proportional recovery model for the upper extremity after an ischemic stroke. Neurorehabil Neural Repair. 2015;29:614-622.

[14] Prabhakaran S, Zarahn E, Riley C, et al. Inter-individual variability in the capacity for motor recovery after ischemic stroke. Neurorehabil Neural Repair. 2008;22:64-71.

[15] Nakayama H, Jorgensen HS, Raaschou HO, et al. Recovery of upper extremity function in stroke patients: the Copenhagen stroke study. Arch Phys Med Rehabil. 1994; 75:394-398.

[16] Lee YY, Lin KC, Cheng HJ, et al. Effects of combining robotassisted therapy with neuromuscular electrical stimulation on motor impairment, motor and daily function, and quality of life in patients with chronic stroke: a double-blinded randomized controlled trial. J Neuroengineering Rehabil. 2015;12:96.

[17] Hughes AM, Burridge $\mathrm{JH}$, Demain $\mathrm{SH}$, et al. Translation of evidence-based assistive technologies into stroke rehabilitation: users' perceptions of the barriers and opportunities. BMC Health Serv Res. 2014;14:124.

[18] Bos RH, Haarman CJW, Stortelder T, et al. A structured overview of trends and technologies used in dynamic hand orthoses. J Neuroengineering Rehab. 2016;13:2-25.

[19] Mehrholz J, Hadrich A, Platz T, et al. Electromechanical and robot-assisted arm training for improving generic activities of daily living, arm function, and arm muscle strength after stroke. Cochrane Database Syst Rev, 2012;6:CD006876.

[20] Carpaneto JMS. Application of orthoses and neurostimulation in neurorehabilitation in: Oxford book of neurorehabilitation. In: Christopher K, editor. 1sted. Oxford (UK): Oxford University Press; 2015. p. 263-273.

[21] Mehrholz J, Pohl M, Platz T, et al. Electromechanical and robot-assisted arm training for improving activities of daily living, arm function, and arm muscle strength after stroke. Cochrane Database Syst Rev. 2015;11:CD006876.

[22] Rymer WZ, Jayaraman A. Promises and challenges of neurorehabilitation technology. In: Christopher K, editor. Oxford textbook of Neurorehabilitation. 1st ed. Oxford (UK): Oxford University Press; 2015.

[23] Maciejasz P, Eschweiler J, Gerlach-Hahn K, et al. A survey on robotic devices for upper limb rehabilitation. J Neuroeng Rehabil. 2014;11:3.

[24] Franck JA, Timmermans AA, Seelen HAM. Effects of a dynamic hand orthosis for functional use of the impaired upper limb in sub-acute stroke patients: a multiple single case experimental design study. Technol Disabil. 2013;25:177-187.

[25] Davenport S. Recovery with grasp? A report on a preliminary study investigating the short and medium term effects of the SaeboFlex (FTM System) on chronic post stroke patients with residual upper limb deficit. Synapse. 2005;Spring:12-15. 
[26] de Araujo RC, Rocha DN, Pitangui AC, et al. The influence of dynamic orthosis training on upper extremity function after stroke: a pilot study. J Healthc Eng. 2014;5:55-66.

[27] Langhorne P, Coupar F, Pollock A. Motor recovery after stroke: a systematic review. Lancet Neurol. 2009;8:741-754.

[28] Kutner NG, Zhang R, Butler AJ, et al. Quality-of-life change associated with robotic-assisted therapy to improve hand motor function in patients with subacute stroke: a randomized clinical trial. Phys Ther. 2010;90:493-504.

[29] Burridge $\mathrm{JH}$, Hughes AM. Potential for new technologies in clinical practice. Curr Opin Neurol. 2010;23:671-677.

[30] Dixon G, Thornton EW, Yound CA. Perceptions of self-efficacy and rehabilitation among neurologically disabled adults. Clin Rehabil. 2007;21:230-240.

[31] Barlow D, Nock MK, Hersen M. Single case experimental designs: strategies for studying behavior change. Cambridge: Pearson Publishing; 2008.

[32] Yang $F$, Zhang $X$, Xie $X$, et al. Intramuscular nerve distribution patterns of anterior forearm muscles in children: a guide for botulinum toxin injection. Am J Transl Res. 2016;15:5485-5493.

[33] Daube JR, Rubin Dl, editors. Compound muscle action potentials. In: Clinical neurophysiology. 3rd ed. Oxford: Oxford press; 2009. p. 327-367.

[34] Franck JA, Halfens JAM, Smeets RJEM, et al. Concise arm and hand Rehabilitation Approach in Stroke (CARAS): a practical and evidence-based framework for clinical rehabilitation management. Open J Occup Ther. 2015; 3:10.

[35] Hsieh CL, Hsueh IP, Chiang FM, et al. Inter-rater reliability and validity of the action research arm test in stroke patients. Age Ageing. 1998;27:107-113.

[36] Lyle RC. A performance test for assessment of upper limb function in physical rehabilitation treatment and research. Int J Rehabil Res. 1981;4:483-492.

[37] Weerdt de WHM. Measuring recovery of arm-hand function in stroke patients: a comparison of the Brunnstrom-FuglMayer test and the action research arm test. Physiother Can. 1985;37:65-70.

[38] van der Lee JH, Roorda LD, Beckerman H, et al. Improving the action research arm test: a unidimensional hierarchical scale. Clin Rehabil. 2002;16:646-653.

[39] Lang CE, Edwards DF, Birkenmeier RL, et al. Estimating minimal clinically important differences of upper-extremity measures early after stroke. Arch Phys Med Rehabil. 2008;89:1693-1700.

[40] Deci EL, Eghrari $\mathrm{H}$, Patrick BC, et al. Facilitating internalization: the self-determination theory perspective. J Pers. 1994;62:119-142.

[41] Johnson MJ, Loureiro RCV, Harwin WS. Collaborative telerehabilitation and robot-mediated therapy for stroke rehabilitation at home or clinic. Intel Serv Robotics. 2008; 1:109-121.
[42] Tsigilis N, Theodosiou A. Temporal stability of the intrinsic motivation inventory. Percept Mot Skills. 2003;97:271-280.

[43] Barry JG, Ross SA, Woehrle J. Therapy incorporating a dynamic wrist-hand orthosis versus manual assistance in chronic stroke: a pilot study. J Neurol Phys Ther. 2012; 36:17-24.

[44] Jones F, Mandy A, Partridge C. Changing self-efficacy in individuals following a first time stroke: preliminary study of a novel self-management intervention. Clin Rehabil. 2009;23:522-533.

[45] Balasubramanian S, Klein J, Burdet E. Robot-assisted rehabilitation of hand function. Curr Opin Neurol. 2010; 23:661-670.

[46] Masiero S, Poli P, Rosati G, et al. The value of robotic systems in stroke rehabilitation. Expert Rev Med Devices. 2014;11:187-198.

[47] Nycz CJ, Butzer T, Lambercy O, et al. Design and characterization of a lightweight and fully portable remote actuation system for use. IEEE Robot Autom Lett. 2016;1:976-983.

[48] Kwakkel G, Winters C, van Wegen EE, et al. Effects of unilateral upper limb training in two distinct prognostic groups early after stroke: the EXPLICIT-stroke randomized clinical trial. Neurorehabil Neural Repair. 2016;30:804-816.

[49] Marquez-Chin C, Marquis A, Popovic MR. EEG-triggered functional electrical stimulation therapy for restoring upper limb function in chronic stroke with severe hemiplegia. Case Rep Neurol Med. 2016;2016:11.

[50] Popovic DB, Popovic MB. Hybrid assistive systems for rehabilitation: lessons learned from functional electrical therapy in hemiplegics. Conference proceedings: Annual International Conference of the IEEE Engineering in Medicine and Biology Society IEEE Engineering in Medicine and Biology Society Annual Conference. 2006;1:2146-2149.

[51] Winters C, Kwakkel G, Nijland R, EXPLICIT-stroke consortium, et al. When does return of voluntary finger extension occur post-stroke? A prospective cohort study. PloS One. 2016;11:e0160528.

[52] Kwakkel G, Kollen BJ, van der Grond J, et al. Probability of regaining dexterity in the flaccid upper limb: impact of severity of paresis and time since onset in acute stroke. Stroke. 2003;34:2181-2186.

[53] Hayward KS, Kuys SS, Barker RN, et al. Can stroke survivors with severe upper arm disability achieve a clinically important change in arm function during inpatient rehabilitation? A multicentre, prospective, observational study. NeuroRehabilitation. 2014;35:17-23.

[54] Kwah LK, Herbert RD. Prediction of walking and arm recovery after stroke: a critical review. Brain Sciences 2016; 6:53.

[55] Duncan PW, Goldstein LB, Matchar D, et al. Measurement of motor recovery after stroke. Outcome assessment and sample size requirements. Stroke. 1992;23:1084-1089.

[56] WHO. International classification of functioning, disability and health. 2001. 